\title{
OFFICIALS DECISION-MAKING PROCESS IN OPEN SKILL SPORTS, A SYSTEMATIC REVIEW
}

\author{
Eszter Biró, Lászlo Balogh \\ University of Debrecen, Institute of Sport Sciences, Debrecen, Hungary
}

\begin{abstract}
In the ever-accelerating world of sports, decisions are playing a more critical role. The coaches' decisions determine the outcome of the match. The study aimed to review what factors determine the decisions of sports officials in different sports. Today, many former players choose to stay in the sport and continue their activities as coaches. Nonetheless, there is no unified system for determining the experience of coaches. Various factors influence sports officials in their decisions. These can be both external and internal factors. Take the First heuristic leads to more consistent and better decisions. In terms of coaches and referees, the most studied and examined sport is football. Research in other sports appears in minimal numbers.
\end{abstract}

Keywords: decision-making, coach, referee, open skill sports,

\section{THEORETICAL BACKGROUND}

According to Schoemaker (2016), "Decision-making is the process whereby an individual, group, or organization reaches conclusions about what future actions to pursue given a set of objectives and limits on available resources. This process will be often iterative, involving issue-framing, intelligence-gathering, coming to conclusions and learning from, experience" (SCHOEMAKER - RUSSO, 2016).

The decision comprises different elements: perception, attention, thinking, learning, motor skills, technical, tactical readiness, and stress. These psycho-physiological-motor factors can influence decision-making (BALOGH-DONKA, 2020, PUCSOK et al., 2018).

In the world of ever-accelerating sports, the decisions of both players and officials (coaches, referees) have become vital factors (PARADIS et al., 2016). These decisions directly affect the results of matches and competitions (MCCLUNEY et al., 2020). The coaching performance of sports games is based on the quality of the decisions made in matches and competitions (ELSWORTHY et al., 2014). Based on this, it has become essential for professionals dealing with this topic to examine the players and both the referees and the coaches. As a result, the development profile of successful coaches at different levels of sports was examined (GILBERT et al., 2006), as it has recently become common in many sports for senior coaching positions to be filled by former players (SCHINKE et al., 1995). Analyzing their data, it turned out that these coaches had previously spent approximately 1000 hours in various open skill sports as athletes in more than 11 years. This has been called "prior experience" (GILBERT et al., 2006). 
Nevertheless, the grouping of coaching experience to date has not been clearly defined. For years (MESQUITA et al. 2011), based on a license obtained in previous studies, determine coaching experience. In the case of licenses, the given categories are separated, but in terms of years, the different authors define the categories; differently, there is no general value from which the given trainer can be called experienced (LEITE et al., 2011). Two or three groups are distinguished in the literature so far. For the two group classifications, a maximum of 10 years of experience is considered (SERRANO et al., 2013). However, in most cases, three groups are distinguished, where beginners have a professional background of up to 5 years, those with average experience have 5-10 years, and those with experience have at least ten years of experience (VERGEER-LYLE, 2009).

Coaching and player experience influences the decision style. Coaches rarely follow the avoidant style; in general, they tend to be intuitive or rational during decision-making. Coaches with elite experience use intuition more often and better in their decision making than non-experts. The same is true for coaches with elite player experience (GISKE et al., 2013).

In terms of decision style, it is essential to mention Taking the First (TTF) heuristic. Methods that create fewer options induce much better and more consistent decisions (JOHNSON-RAAB, 2003). Adults with high decision-making performance choose the first generated option in the decision-making test (MUSCULUS, 2018). Influencing factors such as mental and physical stress did not change TTF's frequency or the opportunities created first. However, due to mental stress, the first operation was established more slowly; that is, the decision's speed deteriorates (HEPLER, 2015).

The decision-maker (positive, neutral, and negative) can also influence the decision's quality, which supports the importance of the neurovisceral integration model (LABORDE-RAAB, 2013).

For coaches, the match's location, physical well-being, or the expectations of others did not influence decision-making. However, there was a tremendous mental burden on selfexpectation, the quality of preparation, the significance of the result, the coach's gender, the gender of athletes' coaching, the coach's position, and the years of experience (MCCLUNEY, 2020).

In addition to internal factors, several external factors may also play a role in sports officials' current decision-making performance. There is a factor for outdoor athletes that can put obstacles in the way of performance. This is nothing but the weather. During the comfort zone match, the referee's exercise generated a moderate $2.0 \%$ drying up the scene. This dehydration was responsible for decreased somatogenetic, psychomotor, and cognitive performances (HOUSSEIN, 2016).

Additionally, due to the larger audience, there has also been a change in the decisionmaking process, with an increased judgment against the team playing on the away field (BURNETT, 2017).

Concerning another external but decision-making factor - height - several studies have already confirmed the existence of the Napoleonic complex phenomenon, according to which lower people are much punitive than their higher counterparts in order to compensate for their height (KNAPEN et al., 2018). However, this behavior was not an 
observable phenomenon among English referees when judging irregularities. Lower referees award more punishment than higher ones in non-first division leagues (MCCARRICK, 2020).

The relationship between physical fatigue and decision performance was examined in referees both under laboratory conditions (PARADIS, 2016) and within the playing game. During the match, fatigue is characterized by six factors: match period, referee speed, distance traveled, running time, heart rate, blood lactate level, and the decisions made (BLOß, 2020). Further studies showed that referees and assistants worked a mean of 77 $+/-7 \%$ or $85+/-5 \%$ of their pulse rate throughout the matches (HELSEN, 2003). The referee made a mistake when his maximum heart rate was above $85-95 \%$ or $95 \%$. The first situation was in $67.7 \%$ of cases and the second in $26.7 \%$ of cases. Besides, it turned out that due to the increase in the referee's speed, the number of bad judgments

decreased. Furthermore, he made most of the mistakes at speeds of 0-3.6 km/h (GOMEZ, 2016).

The most commonly used proper measurement tool for officials' decision-making in recent times is video-based testing, which takes place off-site in a laboratory environment (Kittel et al., 2019). It aims to improve decision-making skills without special instructions (Larkin et al., 2018). Those who made more successful decisions preferred more targeted search strategies (Vaeyens et al., 2007).

\section{METHODS}

The PRISMA guide informed the process for this systematic review-lines (MOHER et al., 2009), summarised in Figure 1.

\section{SEARCH STRATEGIES}

Electronic databases (Pubmed, ScienceDirect, Human Kinetics Journals, PsycNet, Google Scholar) were searched for with the keyword combinations included "decision making" in conjunction with "coach" and "trainer." The search was restricted to English and Spanish peer-reviewed articles. In the initial search, 193 articles were detected. The keywords of the articles were analyzed for further search combinations. Two new search terms were determined and united with the current terms, including "sport" and "sports officials," and subsequently searched within the databases. A further 81 articles were determined with the new search terms in the five databases, resulting in 274 .

\section{Inclusion and exclusion of studies}

Studies incorporated in this systematic review corresponded to the following criteria: (a) participant groups contained coaches and referees, (b) only officials of open skill sports were taken, (c) participants were head coaches (i.e., second coaches were excluded as decision-making is realized by head coaches during the matches/competitions). 
Vol 3, No 2 (2020): Stadium-Hungarian Journal of Sport Sciences

https://doi.org/10.36439/SHJS/2020/2/8596

\section{Screening articles}

Each article was screened by investigating the title, keywords, and abstract based on the inclusion criteria. If there was any indeterminacy over an article's suitability, this was debated by the first and second authors. 
Vol 3, No 2 (2020): Stadium-Hungarian Journal of Sport Sciences https://doi.org/10.36439/SHJS/2020/2/8596

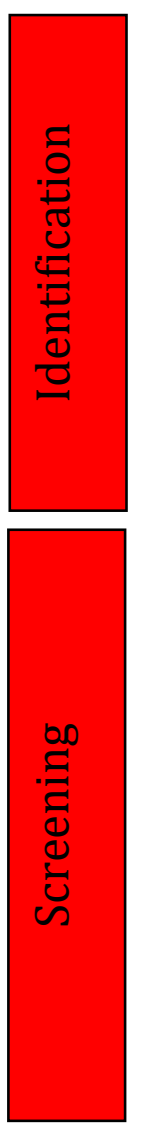

Records identified through database searching

$(n=274)$
Additional records identified through other sources

$$
(n=3)
$$

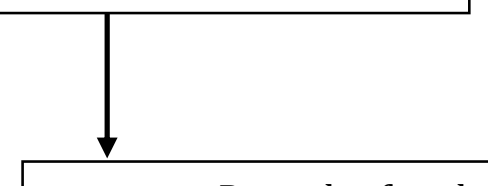

Records after duplicates removed

$(n=240)$
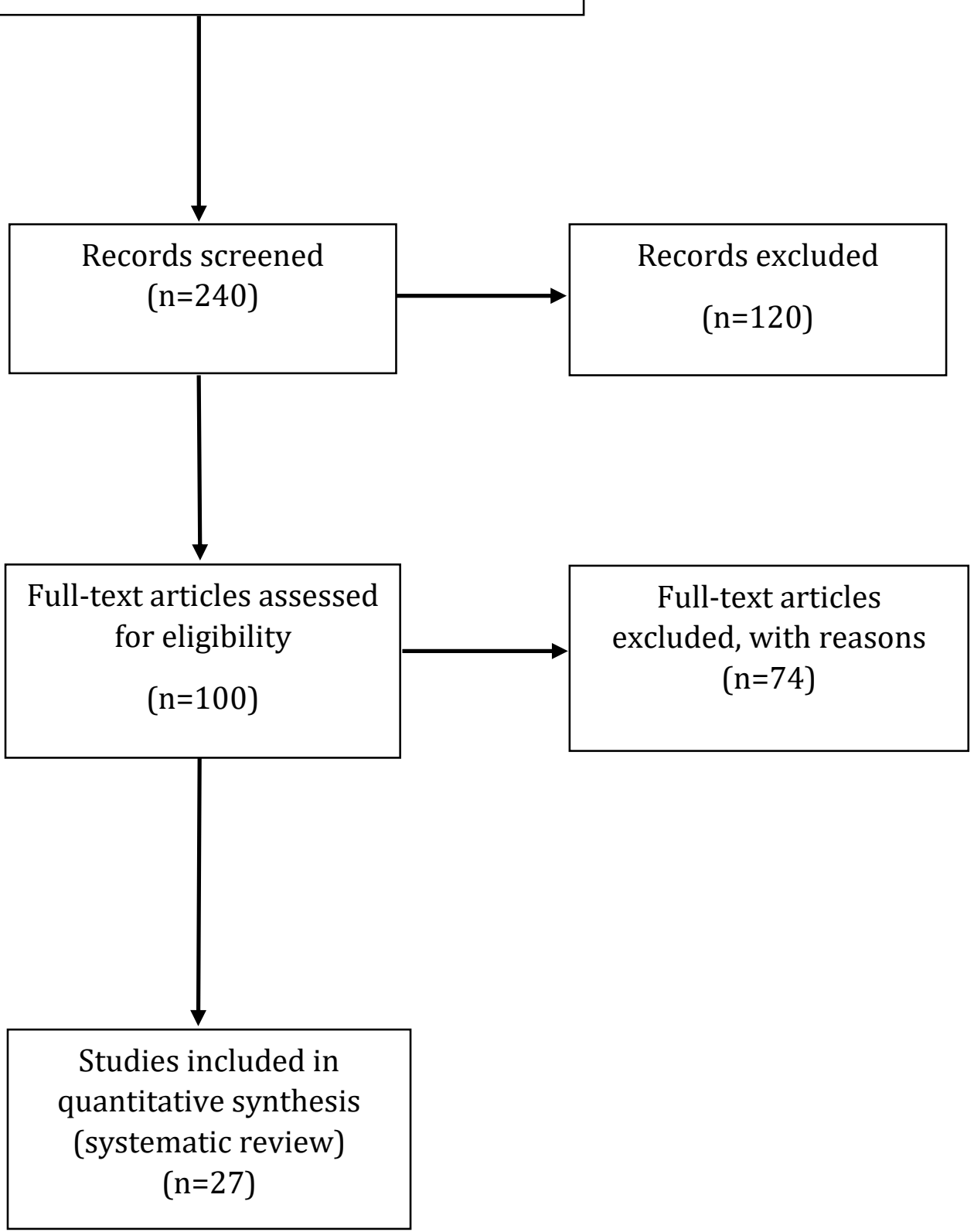

Figure. 1: Diagram of PRISMA flow. 


\section{RESULTS}

To get the answer to what decision factors play a role in international coaches' decisionmaking and referees full-text review of 193 articles was investigated after being determined as potentially relevant from investigating titles, abstracts, and keywords. To ascertain the full-text articles' suitability, these were reexamined and evaluated against the inclusion criteria. We excluded most of the studies because they examined the player's decision-making, not coaches $(n=58)$. Overall, were incorporated 26 studies in the final analysis.

In the studies examined, the most predominant sport investigated was soccer $(\mathrm{n}=23)$, followed by handball $(n=3)$ and water polo $(n=1)$.

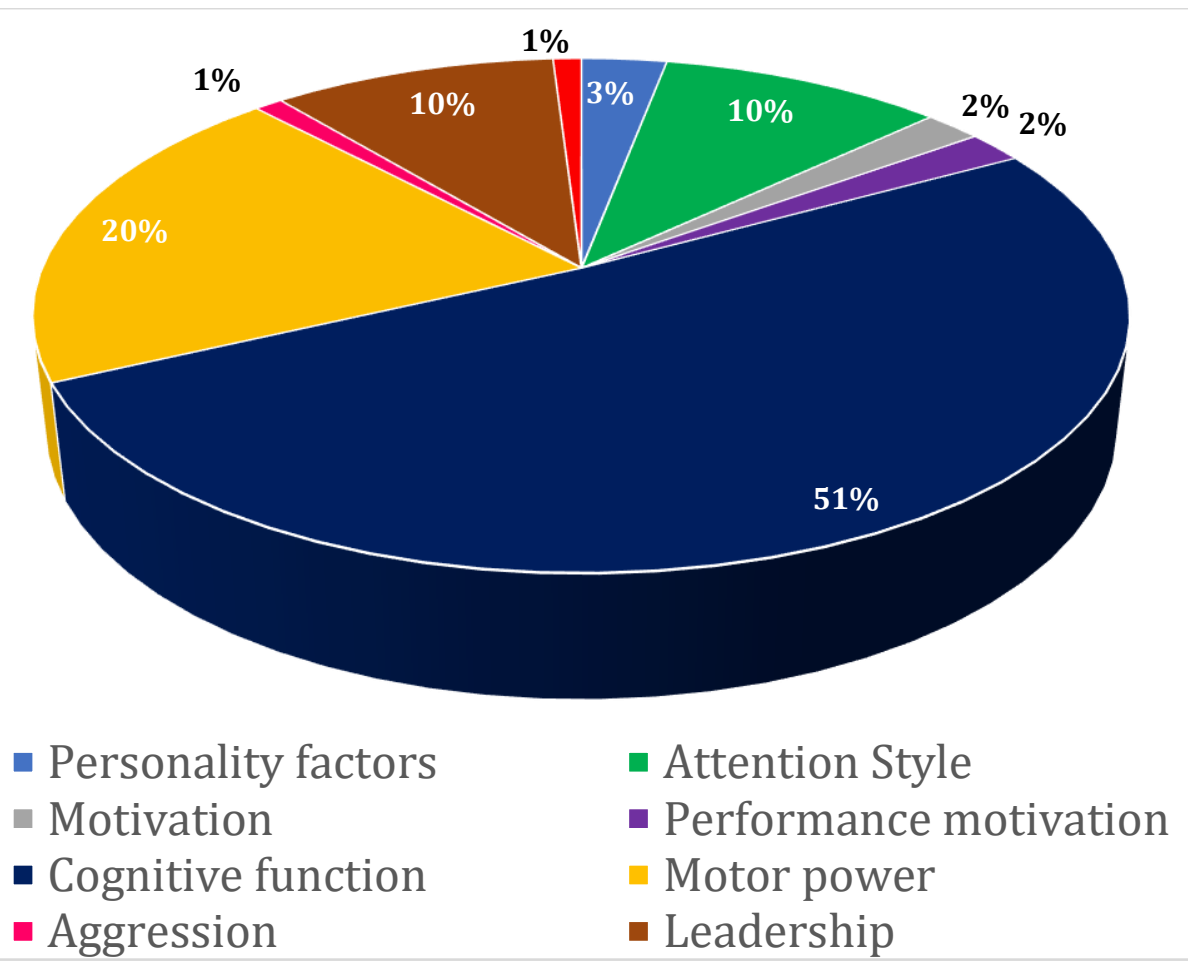

Figure. 2: Decision-making factors of international sports officials, percentage based on the 100 systematic reviews examined

\section{DISCUSSION}

This review's primary purpose was to contribute a summary of decision-making factors and analyze the numerous methods utilized to investigate sports officials' decisionmaking processes. The results highlight different vital findings in the search. (a) Personality, motivation, aggression analysis is not as interesting for researchers. 
Predominantly cognitive skills of sports officials are investigated. The most predominant sport investigated was soccer $(\mathrm{n}=23)$, followed by handball $(\mathrm{n}=3)$ and water polo $(\mathrm{n}=$ 1). According to these findings, we cannot correctly see coaches' decision-making process in open sports, only the case of football sports officials. It would be necessary to extend the research to other sports (i.e., handball, basketball, volleyball, rugby, American football) to see and compare sports officials' decision-making process in all sports.

Also, We would consider it essential to compare the coaches of different nations' decisionmaking mechanisms in each sport. to give the topic greater prominence during coaching training and to adopt the practices of coaches of prosperous nations.

For ease of judgment, it may be necessary to standardize the crediting of experience in years.

This study was supported by the Economic Development and Innovation Operational Programme, 2014-2020 - GINOP 2.3.2.-15-2016-00062.

\section{REFERENCES}

Balogh L., Donka D. B. (2020). Testing game intelligence and stress resilience inexperienced and young team athletes with VTS and innovate, complex MDE Heidelberg stress holter tools. Tanulmánykötet-Trendek a versenysport és a szabadidősport területéről, 4, University of Debrecen, 12-21.

Bloß N., Schorer J., Loffing F., \& Büsch D. (2020). Physical Load and Referees' DecisionMaking in Sports Games: A Scoping Review, J Sports Sci Med, 24, 19(1), 149-157.

Burnett A.M., Bishop D.T., Ashford K.J, Williams A.M., \& Kinrade. N.P. (2017). Decisionmaking of English Netball Superleague umpires: Contextual and dispositional influences, Psychology of Sport and Exercise, 31, 52-60. doi: 10.1016/j.psychsport.2017.04.003

Elsworthy N., Burke D., \& Dascombe J.B. (2014). Factors relating to the decisionmaking performance of Australian football officials, International Journal of Performance Analysis in Sport, 14, 2, 401-410 https://doi.org/10.1080/24748668.2014.11868730

Fogarty G. J. (1995). Some comments on the use of psychological tests in sport setting. International Journal of Sport Psychology, 26 (1), 161-170. 
Gilbert W., Côté. J., \& Mallett. C. (2006). Developmental Paths and Activities of Successful Sport Coaches, International Journal of Sports Science \& Coaching, 1, doi: $10.1260 / 174795406776338526$

Giske R., Benestad B., Haraldstad K., \& Høigaard R. (2013). Decision-Making Styles among Norwegian Soccer Coaches: An Analysis of Decision-Making Style in Relation to Elite and Non-Elite Coaching and Level of Playing History, International Journal of Sports Science \& Coaching, 1, 2013. doi: 10.1260\%2F1747-9541.8.4.689

Gomez-Carmona. C., Pino-Ortega. J. (2016). Kinematic and physiological analysis of the performance of the referee football and its relationship with decision making, Journal of Human Sport and Exercise, 11, 4, 397-414. doi: 10.14198/jhse.2016.114.01

Helsen W., Bultynck J. B. (2003). Physical and perceptual-cognitive demands of topclass refereeing in association football, Journal of Sports Sciences, 22, 2, 179-189. doi:10.1080/02640410310001641502

Hepler T.J. (2015). Decision-making in Sport under Mental and Physical Stress, International Journal of Kinesiology \& Sports Science, 3, 4.

Houssein M., Lopes. P., Fagnoni. B., Ahmaidi. S., Yonis. S.M., \& Leprêtre. P.M. (2016). Hydration: The New FIFA World Cup's Challenge for Referee Decision Making?, J Athl Train, 51, (3), 264-6. doi: 10.4085/1062-6050-51.3.04.

Johnson. J.G., Raab M. (2003). Take The First: Option-generation and resulting choices, Organizational Behavior and Human Decision Processes,91, 2, 215-229. doi: 10.1016/S0749-5978(03)00027-X

Kittel. A., Larkin. P., Elsworthy. N., \& Spittle. M. (2019) Video-based testing in sporting officials: A systematic review. Psychology of Sport \& Exercise 43, 261-270.

Knapen. J. E. P., Blaker. N. M., \& Vugt. M.V. (2018). The Napoleon Complex: When Shorter Men Take More, Psychological Science, 29, (7), 1134-1144. doi: 10.1177/0956797618772822.

Laborde S., Raab M. (2013). The tale of hearts and reason: The influence of mood on decision making., Journal of Sport \& Exercise Psychology, 35(4), 339-357. doi: 10.1123/jsep.35.4.339

Larkin P., Mesagno C., Berry. J., Spittle. M., \& Harvey. J. (2018) Video-based training to improve perceptual-cognitive decision-making performance of Australian football umpires. J Sports Sci, 36, (3), 239-246. 
Leite N., Coelho E., \& Sampaio J. (2011). Assessing the Importance Given by Basketball Coaches to Training Contents, J Hum Kinet., 30, 123-133. doi: 10.2478/v10078-011$0080-3$

McCluney E. N., McCullick B. A., \& Schempp. P. G. (2020). Factors Triggering Pressure on Basketball Coaches' In-Game Decision-Making, The Sport Journal, 41, 2.

Mesquita I., Borges. M., Rosado A., \& Souza A.D. (2011). Handball Coaches' Perceptions About the Value of Working Competencies According to Their Coaching Background, $J$ Sports Sci Med., 10, (1), 193-202.

Moher D., Liberati. A., Tetzlaff J., Altman. D. G., \& Group. P. (2009). Preferred reporting items for systematic reviews and meta-analyses: The PRISMA statement. PLoS medicine, 6, (7), e1000097.

Musculus L., Raab. M., Belling P., \& Lobinger. B.H. (2018). Linking self-efficacy and decision-making processes in developing soccer players, Psychology of Sport and Exercise, 39, 72-80. doi: 10.1016/j.psychsport.2018.07.008

Paradis K., Larkin. P., \& O'Connor. D. (2016). The effects of physical exertion on decision-making performance of Australian football umpires., J Sports Sci., 34, (16), 1535-41. doi: 10.1080/02640414.2015.1122205

Pucsok J. M., Lenténé Puskás A., \& Varga K. et al. (2018). A Multi-Disciplinary Examination of Psycho-Physiological Performance Among Youth and Junior Ball Sport Athletes: A Systematic Review. Exercise Medicine, 2, (2).

Schinke. R. J., Bloom. G. A., \& Salmela. J. H. (1995). The Career Stages of Elite Canadian Basketball Coaches, Avante 1, 48-62.

Schoemaker P. J. H., Russo J. E., (2016). Decision-making, The Palgrave Encyclopedia of Strategic Management, 1-5. doi: 10.1057/978-1-349-94848-2_341-1

Serrano. J., Shahidian. S., Sampaio. J., \& Leite. N. (2013). The Importance of Sports Performance Factors and Training Contents From the Perspective of Futsal Coaches, $J$ Hum Kinet., 30, 38, 151-160. doi: 10.2478/hukin-2013-0055 
Vaeyens R., Lenoir M., Williams A. M., \& Philippaerts R. M. (2007). Mechanisms Underpinning Successful Decision Making in Skilled Youth Soccer Players: An Analysis of Visual Search Behaviors. J Motor Behavior, 39, 5.

Vergeer. I., Lyle. J. (2009). Coaching experience: Examining its role in coaches' decision making, International Journal of Sport and Exercise Psychology, 7, 4, doi:10.1080/1612197X.2009.9671918 